\title{
Decadal variability in a central Greenland high-resolution deuterium isotope record and its relationship to the frequency of daily atmospheric circulation patterns from the North Atlantic region
}

Norel Rimbu ${ }^{1,2,3}$, Gerrit Lohmann ${ }^{1,2}$

${ }^{1}$ Alfred Wegener Institute for Polar and Marine Research, 27570 Bremerhaven, Germany.

${ }^{2}$ University of Bucharest, Faculty of Physics, Department of Atmospheric Physics, Bucharest, Romania.

${ }^{3}$ Climed Norad, Zeicani 25, 040791, Bucharest, Romania.

${ }^{4}$ University of Bremen, Environmental Physics Department and Marum, Bremen, Germany.

Corresponding Author: Norel Rimbu (Norel.Rimbu@awi.de) 


\begin{abstract}
.
The variability of an annual-resolution deuterium time series from central Greenland is investigated in connection with the variability in the frequency of daily atmospheric circulation patterns in the North Atlantic region. Statistical analysis reveals that a large part of the decadal variability of the deuterium isotope record is related to decadal variability in the frequency of several identified daily circulation patterns. We show that these circulation patterns induce variations in the deuterium record by altering where isotopic fractionation occurs, mainly during the passage of the associated air-masses over continental areas. We identify three significant periodic components in the deuterium isotope record at $\sim 12,20$ and 30 years. We show that the $\sim 20$-year signal in the deuterium isotope record is related to the variability in the frequency of a winter circulation type. Analysis of six oxygen isotope records from central Greenland reveals decadal variations similar to the deuterium isotope record. We argue that high-resolution stable isotope records from Greenland ice cores can be used to obtain information about the frequency of certain daily circulation patterns during past periods.
\end{abstract}




\section{Introduction}

In order to assess the presently observed climatic change and possible future changes in climate, it is necessary to fully understand the mechanisms behind past climate variations. During the past decades considerable progress has been made through investigation of physical and chemical properties of ice cores from Greenland (e.g. Vinther et al. 2003). Ice cores from the Greenland ice sheet provide insight into the variability of atmospheric circulation from synoptic (Hanna et al. 2006; Rimbu et al. 2007), interannual and decadal (Appenzeller et al. 1998; Hütterli et al. 2005) to millennial or even longer time scales (Masson-Delmotte et al. 2005).

Stable oxygen and deterium isotopes $\left(\delta^{18} \mathrm{O}\right.$ and $\delta^{2} \mathrm{H}$, respectively) in ice cores are typically used to trace the water movement within the hydrological cycle. Given a sufficiently high accumulation rate and lack of melt events, isotopic signals in ice cores can provide climate records with high temporal resolution. Previous studies identified significant correlations between Greenland isotope records and local temperatures, temperatures and pressures from specific locations, as well as atmospheric teleconnection patterns, in particular the North Atlantic Oscillation (e.g. Appenzeller et al. 1998). Besides atmospheric circulation many other factors contribute to variability in the stable isotopes from ice cores. For example, White et al. (1997b) show that a combination of five variables, winter NAO, solar irradiance, average Greenland coastal temperature, sea surface temperature in the moisture source region and the annual temperature seesaw between Jakobshaven and Oslo, describes about 50\% ( $\mathrm{r}=0.71)$ of the variability of stable isotopes from Greenland (Summit) ice cores.

While NAO is clearly reflected in specific ice core records from Greenland (e.g. Vinther et al. 2003), it does not dominate the variability in all parts of the Greenland ice sheet and does not necessarily control the variability in all the Greenland ice core records (Crüger et al. 2004). Recent studies (Hütterli et al. 2005; Fischer and Mieding, 2005) used an alternative approach to the NAO-Greenland relationship and determined 
the synoptic atmospheric circulation patterns that are responsible for the variability of different quantities, i.e snow accumulation, multiple chemical components, etc., from various regions of the Greenland ice sheet. Synoptic scale phenomena, like cyclone frequency variations, are related to primary modes of Greenland snow accumulation (Rogers et al. 2004). Atmospheric blocking was related to snow accumulation in southern Greenland (Hanna et al. 2005) and with variability in ice accumulation in northern Greenland (Rimbu et al. 2007).

Here we apply the same approach to investigate the relationship between decadal variations in a well-dated, high-resolution (annual) deuterium isotope record from the GISP2 core (Barlow et al. 1993; Barlow 1999) and decadal variability in the frequency of daily circulation patterns in the North Atlantic region (Philipp et al. 2007). In contrast to previous studies, which have used relatively short data sets to investigate the relationships between synoptic scale phenomena and climate variability as reflected in various proxy data from Greenland, we use relatively long records (154 years) of frequency of daily circulation patterns from the North Atlantic regions. We show that an important part of decadal variability in the deuterium isotope record is related to decadal variability in the frequency of few winter and summer daily circulation patterns.

The paper is organized as follows. Data and methods are presented in section 2 . The relationship between deuterium variability and frequency of the dominant daily patterns from the North Atlantic region is discussed in section 3. Three significant periodic signals are identified in the deuterium isotope record and the relationship to the frequency of daily circulations are discussed in section 4. Discussion and main conclusions follow in sections 5 and 6 , respectively.

\section{Data and Methods}

The main quantity used in this study is the annual resolution time series of deuterium isotope $\left(\delta^{2} \mathrm{H}\right)$ from central Greenland $\left(72.6^{\circ} \mathrm{N}, 38.5^{\circ} \mathrm{W}\right.$, elevation 3210 
m)(Barlow 1999). This record covers the period 1300 to 1985 (686 years) with annual resolution (Fig. 1) and is archived in the online environmental data base PANGAEA (http://www.pangaea.de). A detailed description of this record can be found elsewhere (Barlow 1999 and the reference therein). Because we are interested in decadal variations of this record, first we linearly detrend this time series and then apply a 7-year running mean filter. These variations are related to the decadal variations in the frequency of daily atmospheric circulation in the North Atlantic region and other climatic fields. In order to test robustness of the results other filter techniques are applied to isolate the decadal component but the results are very similar to those based on running means.

$\delta^{18} \mathrm{O}$ values were extracted from six recently available high resolution Greenland ice core records (http://www.pangaea.de; White 2009a-f) in order to be compared with the deuterium variability and atmospheric circulation patterns. The six records are stacked $\delta^{18} \mathrm{O}$ from cores GRIP, GRIP891, GRIP892, GRIP893, GRIP912, and GRIP913 (respectively White 2009a, 2009b, 2009c, 2009d, 2009e, 2009f). We henceforth refer to these $\mathrm{W} 1, \mathrm{~W} 2, \mathrm{~W} 3, \mathrm{~W} 4, \mathrm{~W} 5$, and W6, respectively. Before statistical analysis these time series were detrended, smoothed with an 7-year running mean filter and normalized with the corresponding standard deviation.

The daily atmospheric circulation patterns used in this paper were obtained from a long-term daily SLP reconstruction reconstruction from the European and North Atlantic Daily to Multidecadal Climate Variability (EMULATE) project (Ansell et al. 2006). These daily patterns were derived using a clustering scheme that combines the concepts of simulated annealing and diversified randomization (SANDRA), which is a more stable statistical scheme compared to the commonly used k-means method (Philipp et al. 2007). Application of the SANDRA algorithm to daily atmospheric circulation in the EMULATE region $\left(20^{\circ} \mathrm{N}-75^{\circ} \mathrm{N} ; 70^{\circ} \mathrm{W}-40^{\circ} \mathrm{E}\right)$ can be optimally represented by $9,11,6$ and 8 patterns in winter (DJF), spring (MAM), summer (JJA) and autumn (SON), respectively (Philipp et al. 2007). In 
total, 34 patterns characterize the atmospheric circulation over the whole year.The seasonal frequencies of these patterns (available online at the EMULATE project webpage http://www.cru.uea.ac.uk/cru/projects/emulate), are used in a composite and correlation analysis to identify which daily pattern from which season is significantly related to deuterium isotope variability. Based on the time series of the correlation coefficients (normalized as a whole for all clusters) of these patterns with daily SLP anomalies (available the EMULATE web page), we identify the atmospheric circulations associated with the high frequency of daily patterns that are significantly related to deuterium record variability.

The variability of deuterium isotope time series was also investigated in connection with other climatic data. Monthly mean geopotential height and wind fields with $2.5^{\circ} \times 2.5^{\circ}$ horizontal resolution from year 1948 to present were extracted from the NCEP Reanalysis data base (Kalnay et al. 1996; Kistler et al. 2001). The precipitation data used in this study, provided by the NOAA/OAR/ESRL PSD, Boulder, Colorado, USA, (http://www.cdc.noaa.gov/) has a $2.5^{\circ} \times 2.5^{\circ}$ horizontal resolution and covers the period 1979-2008 with monthly resolution. This data set was constructed using a combination of station precipitation measurements and satellite observations. The SST data used in this study were extracted from the Met Office Hadley Centre's sea ice and sea surface temperature data set, HadISST1, which has $1^{\circ} \times 1^{\circ}$ horizontal resolution and covers the 1870 to present period with monthly resolution (Rayner et al. 2003).

Using the Multitaper Method (Ghil et al. 2002), we investigate possible periodic signals in the deuterium isotope record as well as in the frequency of daily circulation patterns. 


\section{Deuterium isotope decadal variability and the associated daily circulation patterns}

The annual resolution deuterium isotope time series (Barlow 1999) is presented in Fig. 1 for the period 1300 to 1985. Strong decadal variation is apparent throughout the 700-year time series, indicating that the decadal variation in deuterium during the last century is not unusual.

To identify the daily atmospheric circulation patterns related to deuterium isotope decadal variability we correlate the filtered (7-year running mean) deuterium isotope time series with the filtered (7-year running mean) time series of the frequency of daily circulation patterns. The deuterium isotope time series is significantly ( $95 \%$ confidence level) negatively correlated to the frequency of cluster 5 of winter circulation and cluster 2 of summer circulation and significantly positively correlated to the frequency of cluster 8 of winter circulation on decadal time scales (Fig. 2a). To test the stability of the correlation we calculate the correlation between winter (Fig. 2b) and summer (Fig. 2c) cluster frequencies and the deuterium isotope time series in a 71-year moving window. The correlation between the deuterium isotope time series and the frequency of cluster 5 of winter circulation shows only negative values of the correlation coefficients for all windows covering the period 1950-2003 (Fig. 2b). A similar variation is recorded for the NAO-like pattern 1 of winter circulation (Fig. 2b). The correlation increases slowly as the window moves toward present days. The correlation coefficient between the deuterium isotope record and the frequency of cluster 8 of winter circulation shows variations opposite to those of patterns 1 and 5 (Fig. 2b). Correlations of the frequency of the other winter patterns and deuterium isotope time series are smaller than the corresponding correlations of pattern 5 and pattern 8 (Fig. 2b). The correlation between the frequency of pattern 2 of summer circulation and deuterium isotope record is negative for all windows covering the period 1850-2003 and shows small decadal 
variations (Fig. 2c). The correlations of deuterium record with the frequency of the other 5 summer patterns are relatively small and show strong decadal variations (Fig. 2c). To better asses and confirm the results of correlation analysis we average the frequency of daily patterns when deuterium isotope anomaly was higher than one standard deviation and compared with the corresponding frequencies averaged over the periods when deuterium anomaly was lower than minus one standard deviation. This composite analysis confirms the results of correlation analysis. The frequency of only few patterns varies significantly for high to low deuterium periods. A significant (95\% level) increase (decrease) from low to high deuterium isotope years is detected for cluster 8 of winter circulation (cluster 5 of winter circulation and cluster 2 of summer circulation). No significant difference in the frequency of the other clusters for high and low deuterium years were detected (not shown).

Since the spatial structures of the clusters are already published (Philipp et al. 2007) and available online via the EMULATE webpage, we present here only the clusters that are significantly related to the deuterium isotope record at decadal time scales, i.e. clusters 5 and 8 of winter circulation and cluster 2 of summer circulation (Fig. 3). These patterns were obtained by averaging the daily SLP anomalies for the days when the correlation coefficient between the original cluster derived with the SANDRA algorithm (Philipp et al. 2007) and daily SLP pattern was higher than one standard deviation. Pattern 5 of winter circulation shows a low pressure centre over Scandinavia and a high pressure centre over the Atlantic (Fig. 3a). High frequency of this pattern is associated with cold and dry conditions over Greenland. Pattern 8 of winter circulation, an anomalous southwest-northeast wavetrain (Fig. 3b), corresponds to a high pressure bridge over Europe and a relatively low pressure over the Mediterranean. High (low) frequency of this pattern is associated with warm (cold) winter conditions over a large part of Greenland. Pattern 2 of summer circulation has a wave-like structure with positive SLP anomalies over most of the North Atlantic and negative SLP anomalies 
over the Scandinavian region and Greenland regions (Fig. 3c). It corresponds to a retreated Azores high and enhanced cyclonic influence over Scandinavia leading to cold conditions over Greenland.

Clusters that are significantly related to deuterium isotope variability were derived using SLP data from the North Atlantic region (Philipp et al. 2007). To identify the large-scale circulation associated to these clusters, we averaged G500 anomalies during days when a certain cluster dominated the surface circulation. The common period of NCEP reanalysis and EMULATE data is 1948-2003. Cluster 5 of winter circulation is associated with a wave train that emanates from the North Pacific (Fig. 4a). Relatively warm air from the North Pacific is advected northward over the North American continent and then southward over Greenland. Furthermore, the pattern shows negative anomalies over the Scandinavian region and positive ones over the eastern North Atlantic Ocean leading to depletion over the European continent (Fig. 4a).

The SST anomalies during the periods when the frequency of this pattern is enhanced (Fig. 4b) are consistent with the corresponding atmospheric circulation (Fig. 4a). Negative SST anomalies south of Greenland are related to enhanced cold air advection from the northwest while positive SST anomalies around $40^{\circ} \mathrm{N}$ are related to warm air advection from the southeast. Warm (cold) anomalies in the Scandinavian (tropical Atlantic, eastern Mediterranean) region are related to enhanced advection of warm (cold) air toward these regions during periods when the frequency of this pattern is enhanced. The magnitude of the SST anomalies are relatively small to influence strongly the fractionation processes. Enhanced frequency of this pattern is associated also with negative precipitation anomalies over the central Atlantic and positive precipitation anomalies over a large area stretching from North America to northern Europe (Fig. 4c). More precipitation over northern Europe leads to more negative values in the deuterium isotope record.

The frequency of cluster 5 is significantly negatively correlated to the deuterium 
isotope record (Fig. 2b). This relationship can be understood based on Fig. 5. During their way from the Pacific to Greenland, air masses become depleted in heavy isotopes (i.e. deuterium isotope) through repeated precipitation and evaporation processes. It is conceivable that this is also related to the so-called continental effect (e.g., Gat 2000). The deuterium isotope in the Greenland ice core becomes more negative during enhanced frequency of this pattern. The exact mechanism is, however, beyond the scope of the present investigation.

The patterns associated with cluster 8 of winter circulation (Fig. 5) are opposite to those associated with cluster 5 (Fig. 4). During periods when the frequency of this pattern is relatively high positive temperature anomalies are recorded over Greenland. Also the flux of moisture from the Atlantic toward Greenland is enhanced. Positive SST anomalies dominate the subtropical region and the south Greenland region while negative SST anomalies are recorded in the western central North Atlantic and north of Scandinavia (Fig. 5b). Positive precipitation anomalies dominate the central North Atlantic region while negative precipitation anomalies dominate a southwest to northeast band stretching from the eastern US coast to Scandinavia (Fig. 5c). The positive correlation between the frequency of this circulation pattern and deuterium isotope can be explained in a similar way as for cluster 5 (note the different signs in Fig. 2a). Due to low precipitation associated with this circulation pattern during the way of water vapor toward Greenland (Fig. 5b) a relatively small quantity of heavy isotope is washed out. Therefore more positive $\delta^{2} \mathrm{H}$ will be recorded in Greenland ice core during periods when the frequency of this circulation is enhanced.

Cluster 2 of summer circulation is associated also with a strong perturbation of the circulation from North America toward Greenland (Fig. 6a). Continental air from North America is advected eastward toward Greenland (Fig. 6c). This cold air meets the relatively warm and moist air from the North Atlantic. The result is enhanced precipitation over southwestern Greenland (Fig. 6c) and more negative 
values of deuterium in the Greenland ice cores. The corresponding SST pattern (Fig. $6 \mathrm{~b}$ ) is similar to that associated with cluster 5 of winter circulation (Fig. 4a). It is, however, likely that the SST anomalies of up to half a degree (Fig. 6b) play a minor role on fractionation as compared to the circulation. We note that the effect of the fractionation associated with the summer circulation is even stronger as compared with winter circulation patterns on decadal time scales.

We address the question if the signature of daily circulation patterns in the deuterium record, as described above, can be detected also in other Greenland ice cores. For this purpose we have used six $\delta^{18} \mathrm{O}$ high resolution records from Greenland ice cores recently made available (White 2009a-f). The dominant pattern of decadal variability in these records, which explains $67 \%$ of variance, captures in phase variability of these records. The associated time coefficients (Fig. 7) show variations very similar to those of the deuterium isotope record. The correlation coefficients between PC1 and W1, W2, W3, W4, W5 and W6 are $0.98,0.83,0.74,0.80,0.77$ and 0.78 respectively. The PC1 is significantly negatively correlated $(\mathrm{r}=+0.60)$ with the deuterium isotope time series. We repeated the analysis using different filters and the results were similar. Furthermore, we obtain similar results when the analysis is performed for the period 1850-1920 and 1921-1985. Therefore the patterns are not sensitive to filtering procedure or to the period considered in the analysis.

The decadal variations of deuterium isotope and PC1 of $\delta^{18} \mathrm{O}$ records are out of phase with the decadal variations in the frequency of cluster 2 of summer circulation (Fig. 7). The correlation coefficient is -0.75 and -0.80 respectively, which is higher than the corresponding correlation coefficient with the frequency of cluster 5 (cluster 8) of winter circulation which is $-0.6(+0.5)$ and $-0.65(+0.55)$ respectively. We repeated the analysis using different filtering methods but the results remain qualitatively the same. 


\section{Cyclicities in the deuterium record and associated daily circulation patterns}

The power spectrum of the deuterium isotope record (Fig. 8a) shows enhanced variability at $\sim 30, \sim 20$ and $\sim 12$ years. These periodicities are reported to be present in various ice core records from Greenland (e.g. Hibler and Johnsen, 1970; White et al. 1997a-b). Spectral analysis reveals a strong quasi-bidecadal cycle in the frequency of cluster 8 of winter circulation (Fig. 8b). Furthermore, the filtered deuterium and cluster 8 frequency time series at bidecadal time scales show significant positive correlations. Therefore, enhanced variability in the deuterium record at bidecadal time scales could be induced by the atmospheric circulation through bidecadal fluctuations in the frequency of pattern 8 of winter circulation.

The $\sim 30$ year cycle in the deuterium isotope record (Fig. 8a) is detected also in the power spectrum of cluster 2 of summer circulation, with a clear out-of-phase variation (not shown). This suggests also a possible relationship between this circulation and the 30-year cycle in the deuterium isotope record. Cyclicities with similar periods were detected in other Greenland ice cores (e.g. White et al. 1997a).

The $\sim 12$-year cycle from the deuterium record (Fig. 8a) can also be related to variations in the frequency of circulation patterns. The power spectra of several circulation patterns show significant peaks at these time scales (not shown). A similar cycle was detected in other annually resolved isotopic records from Greenland, including sites in southern Greenland (Dye 3), northern Greenland (Camp Century) and Summit (White et al. 1997b). This periodicity could be related to variations in the frequency of daily circulation patterns which show enhanced variability at these time scales. 


\section{Discussion}

Analysis of Greenland ice core variability is usually performed in connection with atmospheric teleconnection patterns, especially with the NAO (Vinther et al. 2003; White et al. 1997a-b). Furtheremore, due to changes in atmospheric circulation, moisture source locations for precipitation in Greenland vary strongly for different phases of the NAO (Sodemann et al. 2008). The variable position of moisture source gives a stronger NAO signal in Greenland ice cores than the variability of SST associated to the two NAO phases (Sodemann et al. 2008). However, NAO does explain just part of the variability in certain proxy records from Greenland (Hütterli et al. 2006). An alternative approach is to establish a direct connection between proxy records from Greenland and synoptic scale phenomena (Hütterli et al. 2005; Fischer and Mieding 2005; Rimbu et al. 2007). In this paper we have analyzed the connection between variations in a high-resolution deuterium isotope from GISP2B ice core and atmospheric circulation at decadal time scales.

Previous studies (Barlow et al. 1993) identified atmospheric circulation patterns associated with high minus low deuterium variability in the Greenland GISP2 ice core. The winter pattern (their Figure 8a) is very similar to the pattern 8 of winter circulation and the opposite phase of pattern 5 of winter circulation as derived from the cluster analysis of long-term daily SLP reconstruction as presented in Fig. 3. A similar pattern is associated with enhanced mineral dust and sea salt deposition in Greenland during winter (Hütterli et al. 2006; their Figure 5). Therefore the seasonal patterns associated to the deuterium variability during winter (Barlow et al. 1993) can be considered as the signature of high (low) frequency of patterns 8 (5) of winter daily circulation. However, the circulation pattern associated with deuterium isotope variability during summer (Barlow et al. 1993; their Figure 8b) does not project on the negative phase of pattern 2 of summer circulation represented in Fig. 3c. This difference could be due to different time scales considered in our and Barlow et al. (1993)'s study. 
Along with the spatial clusters, we identify certain periods in the decadal band. Hibler and Johnsen (1979) identified a dominant oscillation in Greenland ice core isotopic records at a period of 20 years. They speculate that this oscillation is related to the Sun's motion relative to the centre of mass of the solar system which correlates with the sunspot's variation. Enhanced variability at these time scales were also detected in accumulation records from Greenland (Andersen et al. 2006). It could be that strong variability at bidecadal time scales in stable isotope records is induced by pattern 8 of winter circulation. Enhanced variability at bidecadal time scales is detected in different time series of climate mode indices (Dima and Lohmann, 2004; Lohmann et al. 2004). Indeed, in some areas this variability could be attributed to solar irradiance which shows enhanced variability at this time scale (Lohmann et al. 2004). A systematic classification of daily circulation patterns for different regions of the North Atlantic realm shall be performed using an isotope-enabled atmospheric circulation model under different forcings.

\section{Conclusions}

We investigate systematically the relationship between decadal variability in the frequency of daily circulation patterns for each season (Philipp et al. 2007) and decadal variability in annualy resolved deuterium isotope and oxygen isotope records from Greenland ice cores (Barlow et al. 1993; White et al. 1997a,b). It was shown that a large part of decadal variability in the deuterium isotope record is related to decadal variability in the frequency of few daily circulation patterns during both winter and summer. These circulations control the deuterium isotope variability (Barlow et al. 1993) mainly through fractionation processes that occur during the passage of the associated air masses over continental areas. We argue that the related changes in SSTs are of second importance in the fractionation processes that lead to deuterium anomalies as recorded in Greenland ice core data considered here. We find that the 
deuterium isotope record (Barlow et al. 1993) is highly correlated to stable oxygen isotope records from GRIP (White et al. 1997a,b) on decadal time scale, suggesting similar relationships between the Greenland ice core records and the frequency of daily atmospheric circulation patterns on this time scale. A logical next step would be to extend our analysis to a large number of high-resolution Greenland ice cores in relation to the atmospheric circulation patterns that control decadal variability.

Our analysis indicates that strong variability at bidecadal time scales in stable isotope records is induced by pattern 8 of winter circulation. A combination of high-resolution and well- dated proxy data and the frequency of daily circulation patterns could lead to a significant improvement of reconstruction of atmospheric circulation and the associated anomalies, especially of the extreme phenomena. Recent work identify such synoptic variability in models and data (Raible et al., 2007; 2008; Pfahl et al., 2009).

We have shown that high-resolution records from central Greenland contain valuable information about the decadal variability in the frequency of daily circulation patterns, as classified by Philipp et al. (2007). We conclude that such records can be used to reconstruct the frequency of seasonal patterns during the past millenium. The information in the ice core records contains a more complex dynamics than the mean temperature, precipitation, or circulation. We suggest to analyze other proxy records in combination with synoptic scale phenomena to obtain a link to the mechanisms responsible for proxy data variability.

Acknowledgments: This study was funded by Alfred Wegener Institute for Polar and Marine Research, Bremerhaven, Germany through the programmes ESSReS and PACES. We thank J. White and L.K. Barlow for making the ice core data available through PANGAEA data base. We thank also to A. Philipp for making the frequency of daily circulation circulation patterns available. We thank also to the two anonymous reviewers for their constructive comments. 


\section{References}

Andersen, K.K., P.D. Ditlevsen, S.O. Rasmussen, H.B. Clausen, B.M. Vinther, S.J. Johnsen, and J.P. Steffensen, 2006: Retrieving a common accumulation record from Greenland ice cores for past 1800 years. J. Geophys. Res. 111, D15106, doi: 10.1029:2005JD006765.

Appenzeller, C., T.F. Stocker, and M. Anklin, 1998: North Atlantic Oscillation dynamics recorded in Greenland ice cores. Science 282, 446-449.

Ansell, JT., and coauthors, 2006: Daily mean sea level pressure reconstructions for the European-North Atlantic region for the period 1850-2003. J. Climate 19, $2717-2742$.

Barlow, L.K., 1999: GISP2 Stable Isotopes (Deuterium, annual averages). PANGAEA doi:10.1594/PANGAEA.56088.

Barlow, L.K., J.W.C. White, R.G. Barry, J.C. Rogers, and P.M. Grootes, 1993: The North Atlantic oscillation signature in deuterium and deuterium excess signals in the Greenland Ice Sheet Project 2 ice core: 1840-1970. Geophys. Res. Lett. 20, 2901-2904.

Crüger, T., H. Fischer, and H. von Storch, 2004: What do accumulation records of single ice cores in Greenland represent?. J. Geophys. Res., 109, D21110, doi:10.1029/2004JD005014.

Dima, M., G. Lohmann, and I. Dima, 2005: Solar induced and internal climate variability at decadal time scales. Int. Jour. Climatol. 25, 713-733.

Fischer, H., and B. Mieding, 2005: A 1000-year ice core record of annual to multidecadal variations in atmospheric circulation over the North Atlantic. Clim. Dyn., 25, $65-74$.

Gat, J.R. 2000: Atmospheric water balance-the isotopic perspective. Hydrological Processes, 14, 1357-1369.

Ghil, M., and Coauthors, 2002: Advanced spectral methods for climatic time series. 
Rev. Geophys., 40(1), 1.1-1.41. doi: 10.1029:2000RG000092.

Hanna, E., J. McConnell, S. Das, J. Cappelen, and A. Stephens, 2006: Observed and modeled Greenland ice sheet snow accumulation, 1958-2003, and links with regional climate forcing. J. Climate, 19, 344-358.

Hibler, W.D., S.J. Johnsen, 1979: The 20-yr cycle in Greenland ice core records. Nature, 280, 481-483.

Hütterli, M.A., C.C. Raible, and T.F. Stocker, 2005: Reconstructing climate variability from Greenland ice sheet accumulation: An ERA40 study. Geophys. Res. Lett., 32, L23712 doi:10.1029/ 2005GL024745.

Hütterli, M.A., and Coauthors, 2006: The influence of regional circulation patterns on wet and dry mineral dust and sea salt deposition over Greenland. Clim. Dyn., 2007,28:635-647.doi:10.1007/s00382-006-0211-z.

C.C. Raible, and T.F. Stocker, 2005: Reconstructing climate variability from Greenland ice sheet accumulation: An ERA40 study. Geophys. Res. Lett., 32, L23712 doi:10.1029/ 2005GL024745.

Kalnay, E., and Coauthors, 1996: The NCEP/NCAR 40 year reanalysis project. Bull. Am. Meteorol. Soc., 77,437-471.

Kistler, R., and coauthors, 2001: The NCEP-NCAR 50-year reanalysis: Monthly means, CD-ROM and documentation. Bull. Am. Meteorol. Soc., 82,247-262.

Lohmann, G., N. Rimbu, and M. Dima, 2004: Climate signature of solar irradiance variations: Analysis of long-term instrumental, historical, and proxy data. Int. Jour. Climatol., 24, 1045-1056.

Masson-Delmotte, V., and Coauthors, 2005: GRIP deuterium excess reveals rapid and orbital-scale changes in Greenland moisture origin. Science, 309,118-121. doi: 10.1126/science.1108575.

Pfahl, S., F. Sirocko, K. Seelos, S. Dietrich, A. Walter and H. Wernli, 2009: A new windstorm proxy from lake sediments - a comparison of geological and 
meteorological data from western Germany for the period 1965-2001. J. Geophys. Res., 114, D18106.

Philipp, A., P.M. Della-Marta, J. Jacobeit, D.R. Fereday, P.D. Jones, A. Moberg, and H. Wanner, 2007: Long-term variability of daily North Atlantic-European pressure patterns since 1850 classified by simulated annealing clustering. J. Climate, 20, 4065-4095.

Raible, C. C., P. M. Della-Marta, C. Schwierz, H. Wernli and R. Blender, 2008: Northern Hemisphere extratropical cyclones: A comparisonof detection and tracking methods and different reanalyses. Mon. Wea. Rev., 136, 880-897.

Raible, C. C., M. Yoshimori, T. F. Stocker and C. Casty, 2007: Extreme midlatitude cyclones and their implications for precipitation and wind speed extremes in simulations of the Maunder Minimum versus present day conditions. Clim. Dyn., 28, 409-423.

Rayner, N.A., D.E. Parker, E.B. Horton, C.K. Folland, L.V. Alexander, D.P. Rowell, E.C. Kent, and A. Kaplan, 2003: Global analyses of sea surface temperature, sea ice, and night marine air temperature since the late nineteenth century. $J$. Geophys. Res., 108(D14), 4407. doi 10.1029/2002JD002670.

Rimbu, N., G. Lohmann, and K. Grosfeld, 2007: Blocking signature in ice core records from northern Greenland. Geophys. Res. Lett., 34, L09704. doi:10.1029/2006GL029175.

Rogers, J.C., D. Bathke, E. Mosley-Thompson, and S.-H. Wang, 2004: Atmospheric circulation and cyclone frequency variations linked to the primary modes of Greenland snow accumulation. Geophys. Res. Lett., 31, doi: 10.1029/2004GL021048.

Sodemann, H., V. Masson-Delmotte, C. Schwierz, B.M. Vinther, and H. Wernli, 2008: Inter-annual variability of Greenland winter precipitation sources: 2. Effects of North Atlantic Oscillation variability on stable isotopes in precipitation. $J$. 
Geophys. Res., 113, doi: 10.1029/2007JD009416.

Vinther, B.M., S.J. Johnsen, K.K. Andersen, H.B. Clausen, and A.W. Hansen, 2003: NAO signal recorded in the isotopes of Greenland ice cores. Geophys. Res. Lett., 30, 1387, doi:10.1029/2002GL016193.

White, J.W.C., E.J. Steig, and L.K. Barlow, 1997a: Reconstructing annual and seasonal climatic responses from volcanic events since A.D. 1270 as recorded in the deuterium signal from the Greenland Ice Sheet Project 2 ice core. J. Geophys. Res., 102(D16), 19683-19694 doi:10.1029/97JD00774.

White, J.W.C., L.K. Barlow, D. Fisher, P.M. Grootes, J. Jouzel, S.J. Johnsen, M. Stuiver, and H.B. Clausen 1997b: The climate signal in the stable isotopes of snow from Summit, Greenland: Results of comparisons with modern climate observations. J. Geophys. Res., 102(C12), 26425-26440. doi:10.1029/97JC00162.

White, J.W.C., 2009a: Stable Isotope Stacked Record of ice core GRIP. PANGAEA. doi:10.1594/PANGAEA.712612.

White, J.W.C., 2009b: Stable Isotope Stacked Record of ice core GRIP891.PANGAEA. doi:10.1594/PANGAEA.712613.

White, J.W.C., 2009c: Stable Isotope Stacked Record of ice core GRIP892.PANGAEA. doi:10.1594/PANGAEA.712614.

White, J.W.C., 2009d: Stable Isotope Stacked Record of ice core GRIP893. PANGAEA. doi:10.1594/PANGAEA.712615.

White, J.W.C., 2009e: Stable Isotope Stacked Record of ice core GRIP912.PANGAEA. doi:10.1594/PANGAEA.712616.

White, J.W.C., 2009f: Stable Isotope Stacked Record of ice core GRIP913. PANGAEA. doi:10.1594/PANGAEA.712617.

Received 
Figure 1. Original (thin) and 7-year running mean filtered (thick) deuterium isotope record from central Greenland ice core (Barlow 1999).

Figure 2. a) Correlation coefficients between decadal components (time scales longer than 7 years) of deuterium isotope time series with cluster frequencies during the 18501985 period. Winter (DJF), spring (MAM), summer(JJA) and autumn (SON) circulation is represented by 9, 11, 6 and 8 patterns so that patterns 1-9 stand for winter, 10-20 for spring, 21-26 for summer and 27-34 for autumn. b) Running correlation between deuterium record time series and the time series of winter clusters frequency in a 71years moving window. c) as in b) but for summer clusters. The correlation is plotted at the middle of each window time interval.

Figure 3. a) Sea level pressure anomalies associated with a) cluster 5 of winter circulation b) cluster 8 of winter circulation and c) cluster 2 of summer circulation. (see text for details). Units are hPa.

Figure 4. a) $500 \mathrm{hPa}$ geopotential anomalies associated with cluster 5 of winter circulation. Units are m. b) SST anomalies and c) precipitation anomalies (color) and 850 hPa geopotential (contour) and wind anomalies (vectors) for for winters characterized by high frequency of pattern represented in a) Units are $\mathrm{C}, \mathrm{mm} /$ day and $\mathrm{m} / \mathrm{s}$.

Figure 5. As in Figure 4 but for cluster 8 of winter circulation.

Figure 6. As in Figure 4 but for cluster 2 of summer circulation.

Figure 7. Series of the time coefficients of dominant pattern of decadal variability of six $\delta^{18} \mathrm{O}$ time series from Greenland ice cores (White 2009a-f) (dashed), frequency of cluster 2 of summer circulation (solid-thin) and deuterium time series (solid-thick). The original time series were smoothed with a 7-year running mean filter and normalized by their standard deviation.

Figure 8. Power spectrum of a) deuterium isotope time series and b) the frequency of pattern 8 of winter circulation. No filter was applied to the data before spectral analysis. 


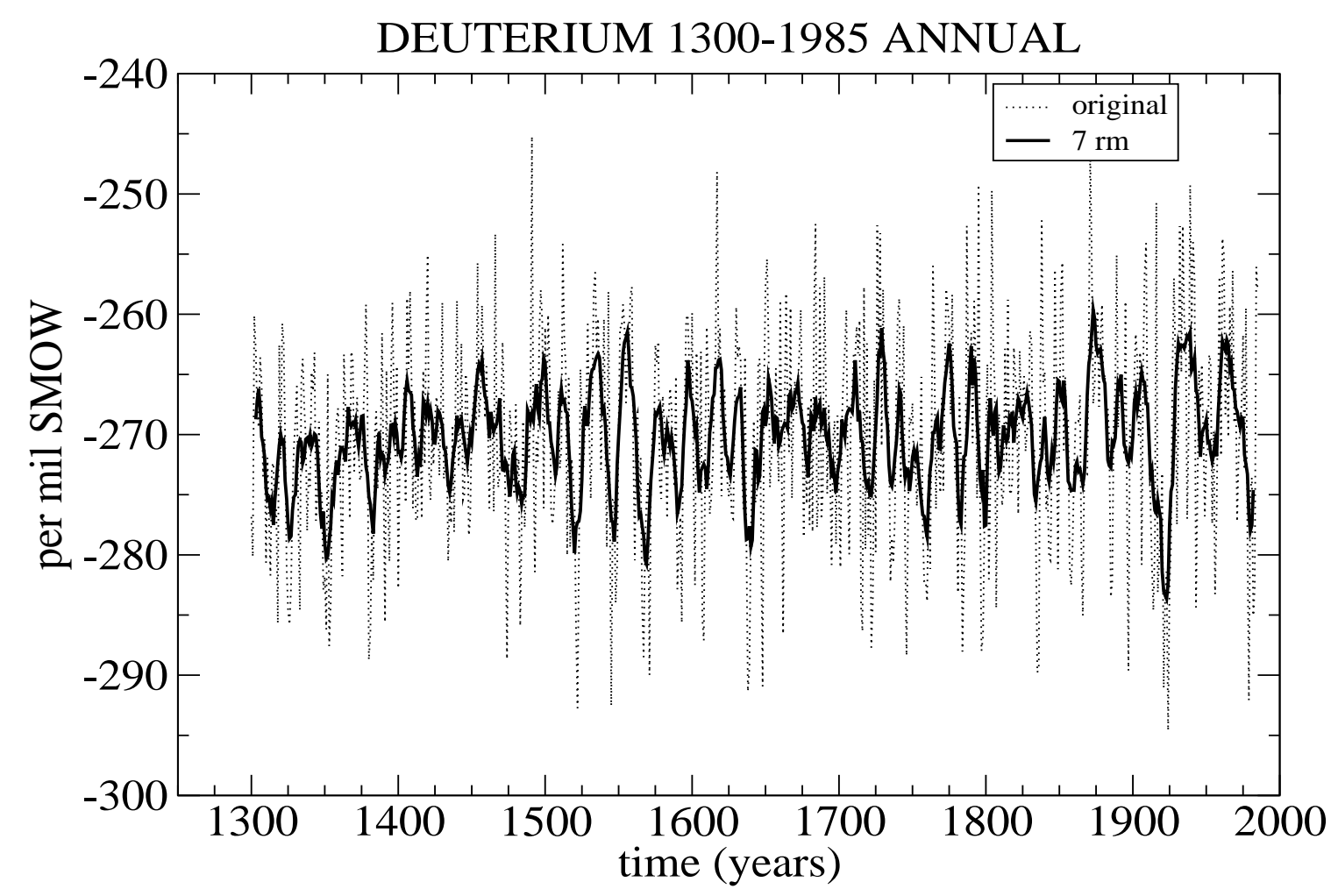

Figure 1: 
a)

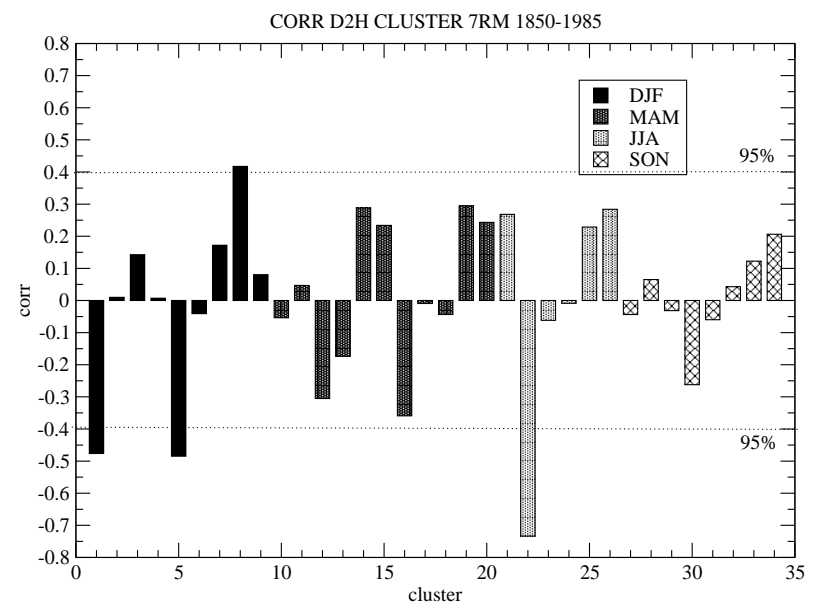

b)

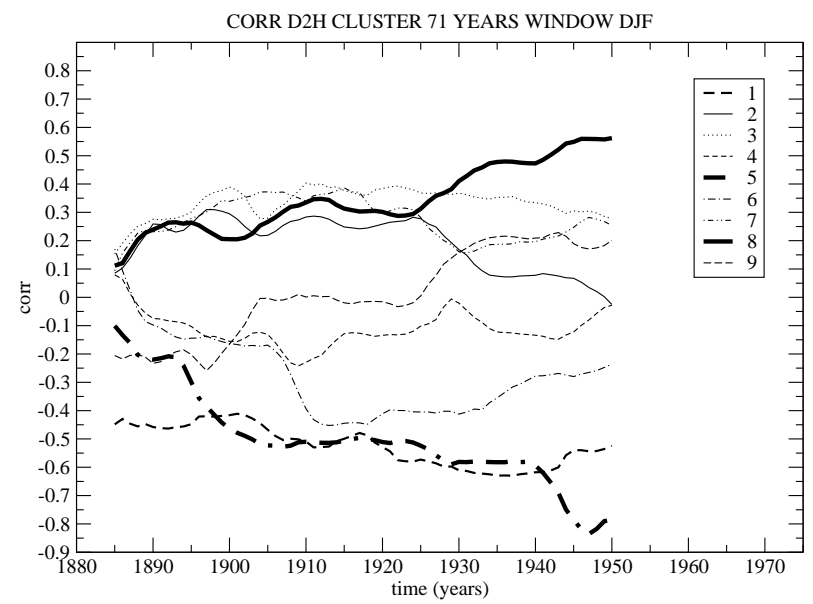

c)

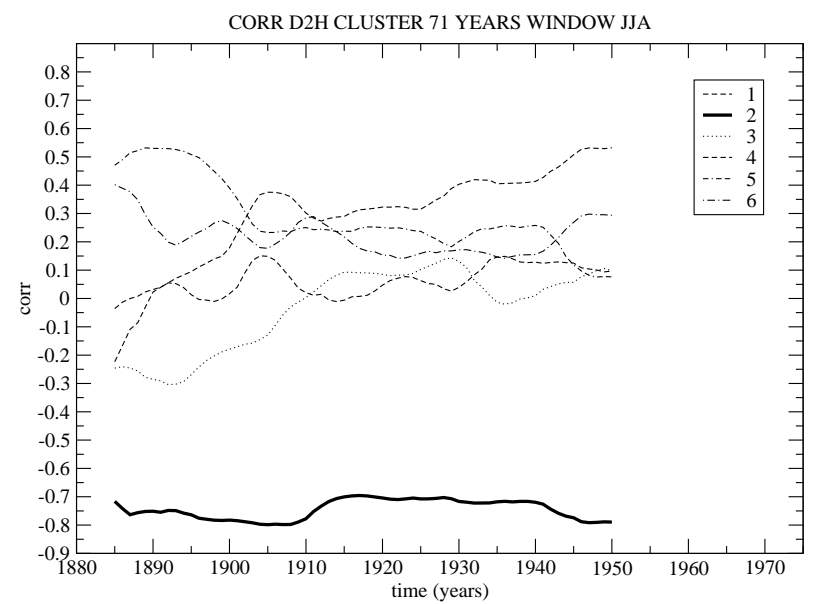

Figure 2: 
a)

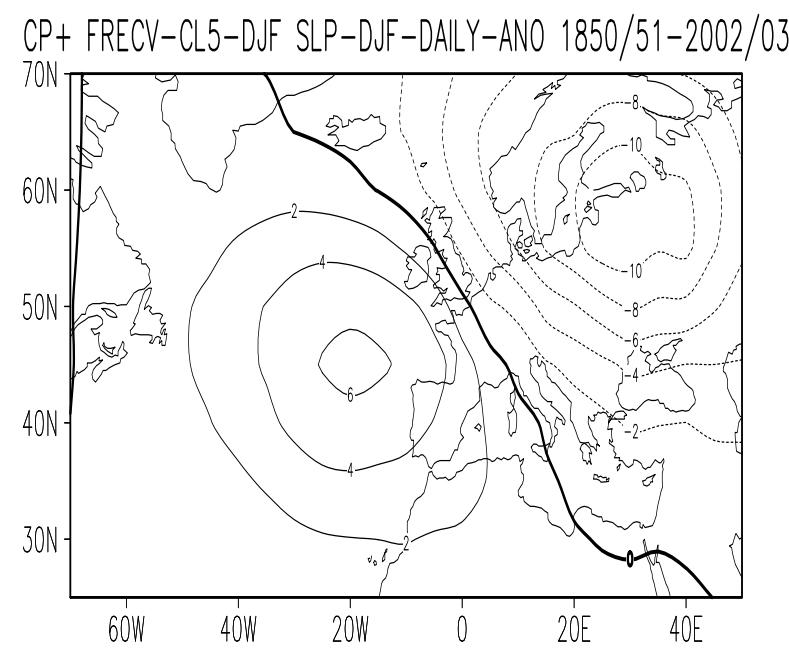

b)

CP+ FRECV-CL8-DJF SLP-DJF-DALY-ANO 1850/51-2002/03

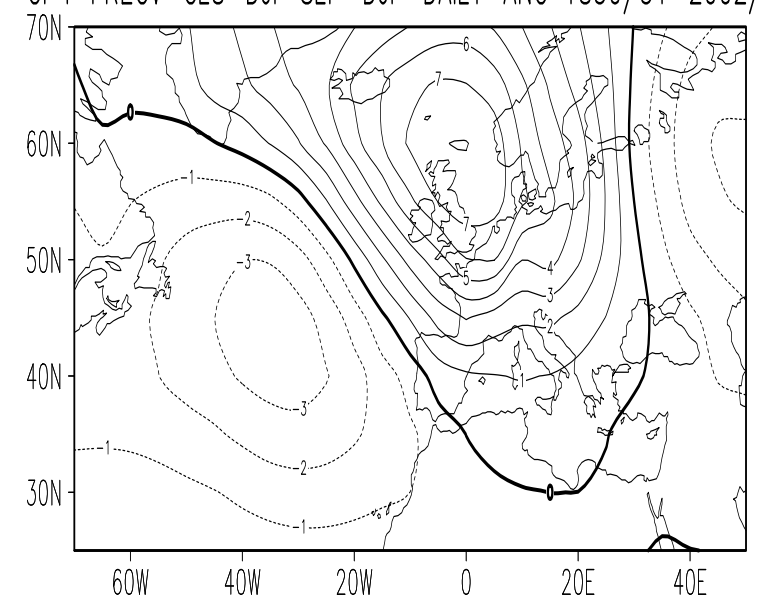

c)

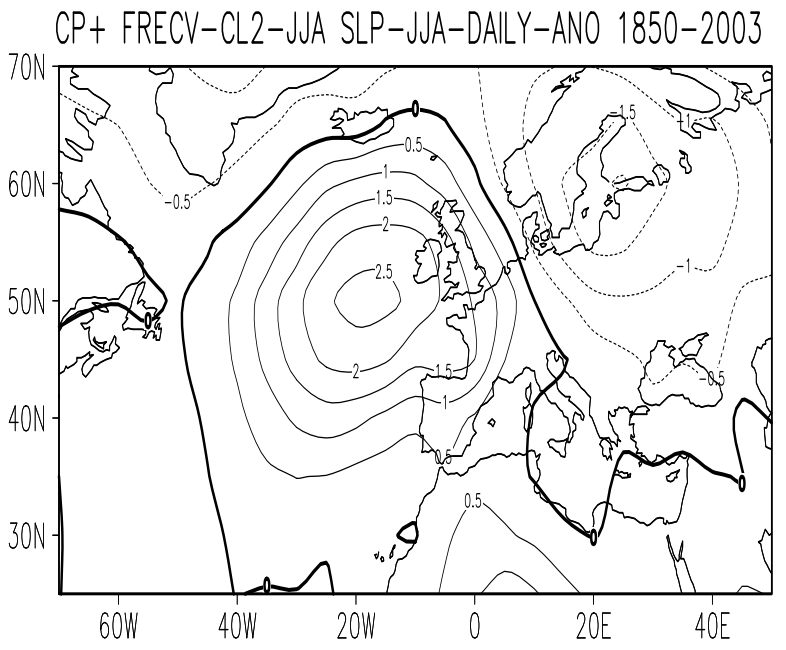

Figure 3: 
a)

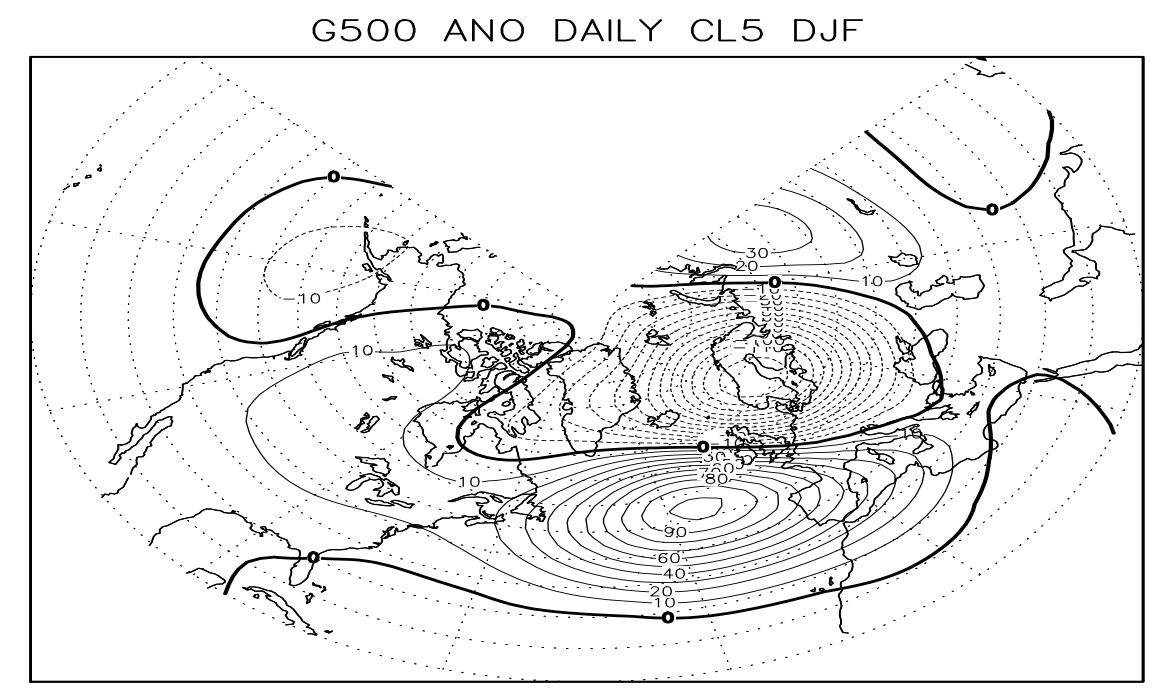

b)

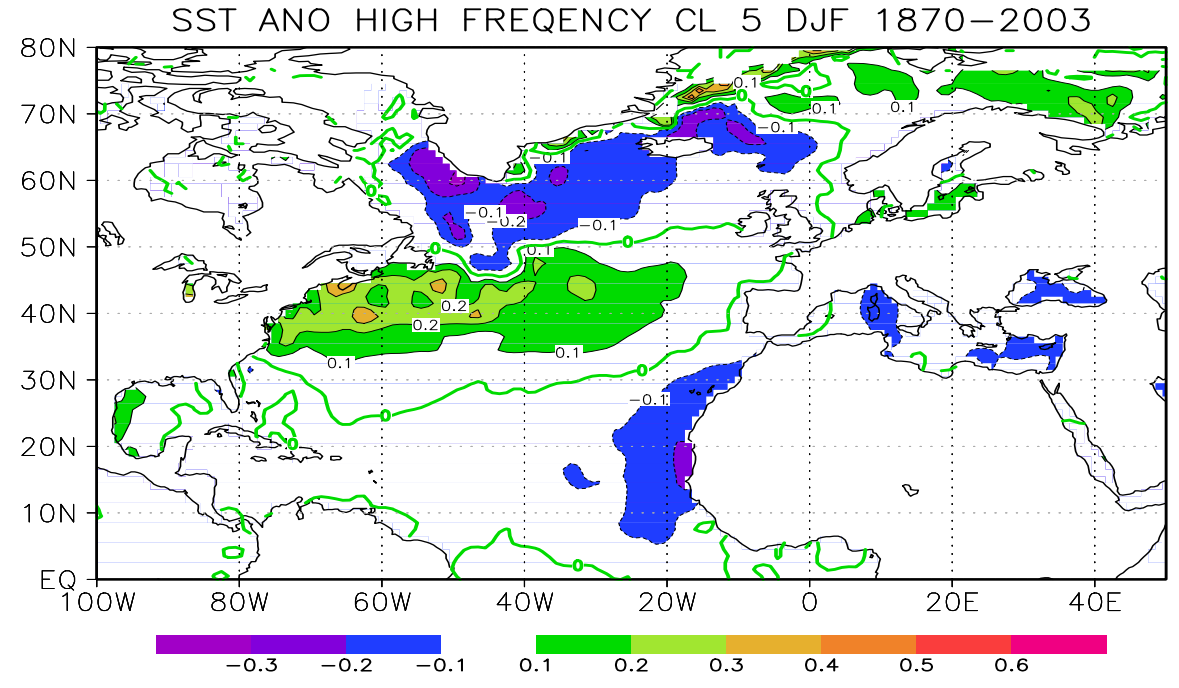

c)

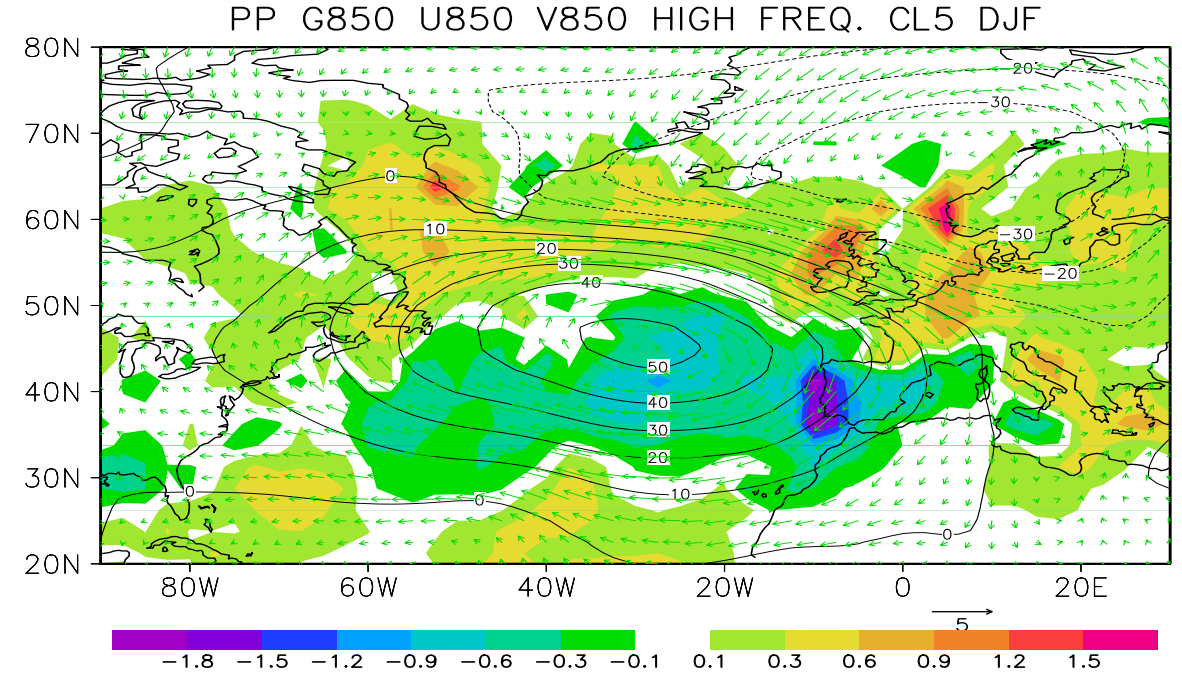

Figure 4: 
a)

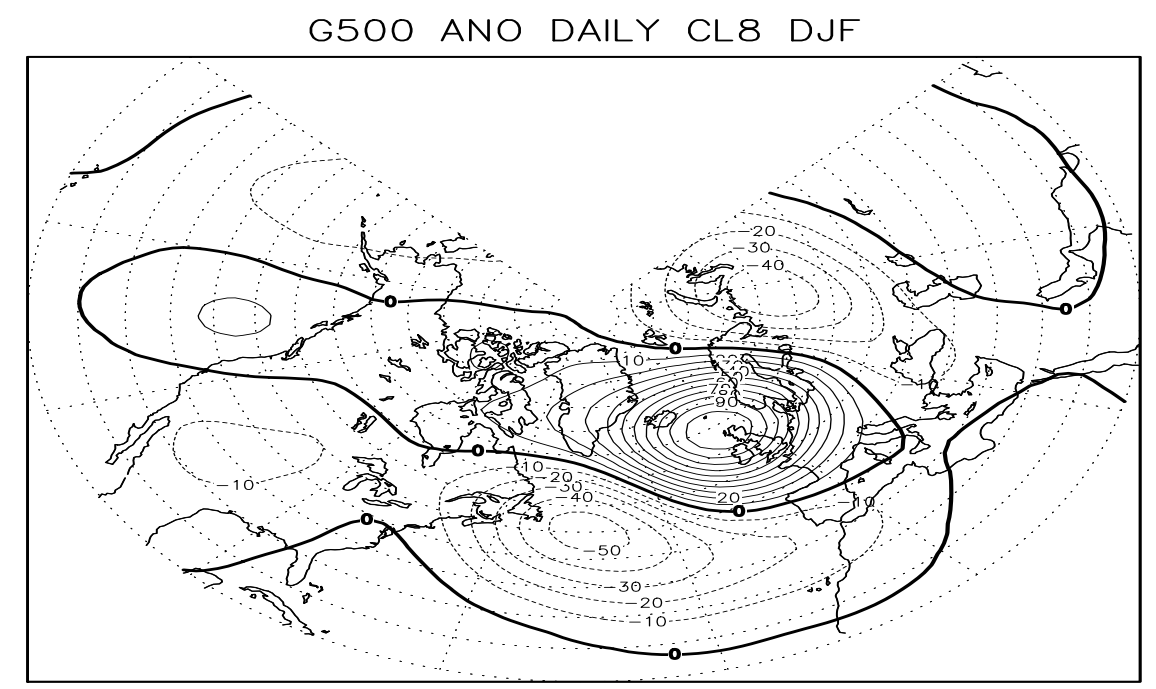

b)

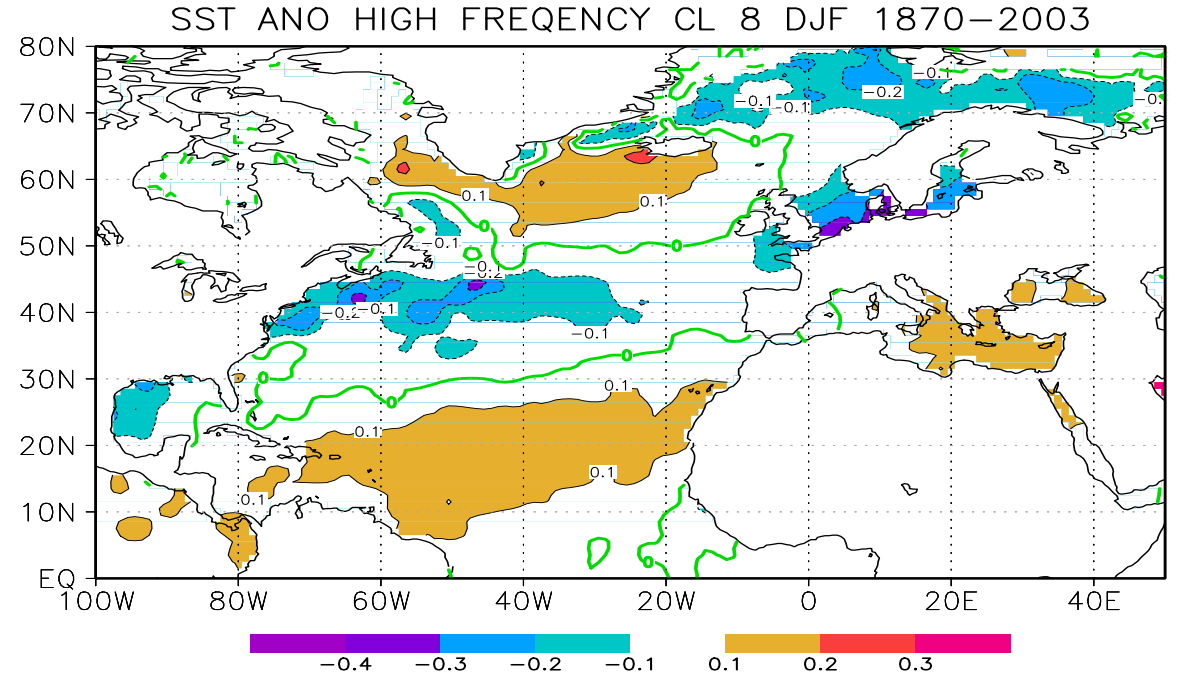

c)

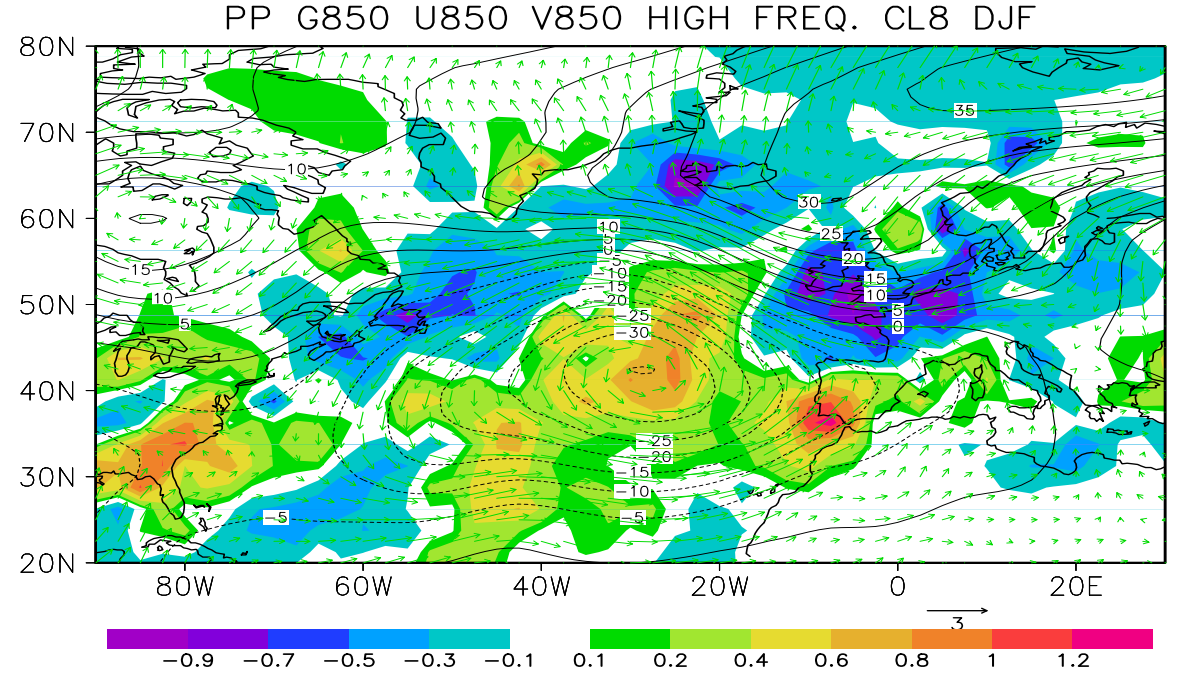

Figure 5: 
a)

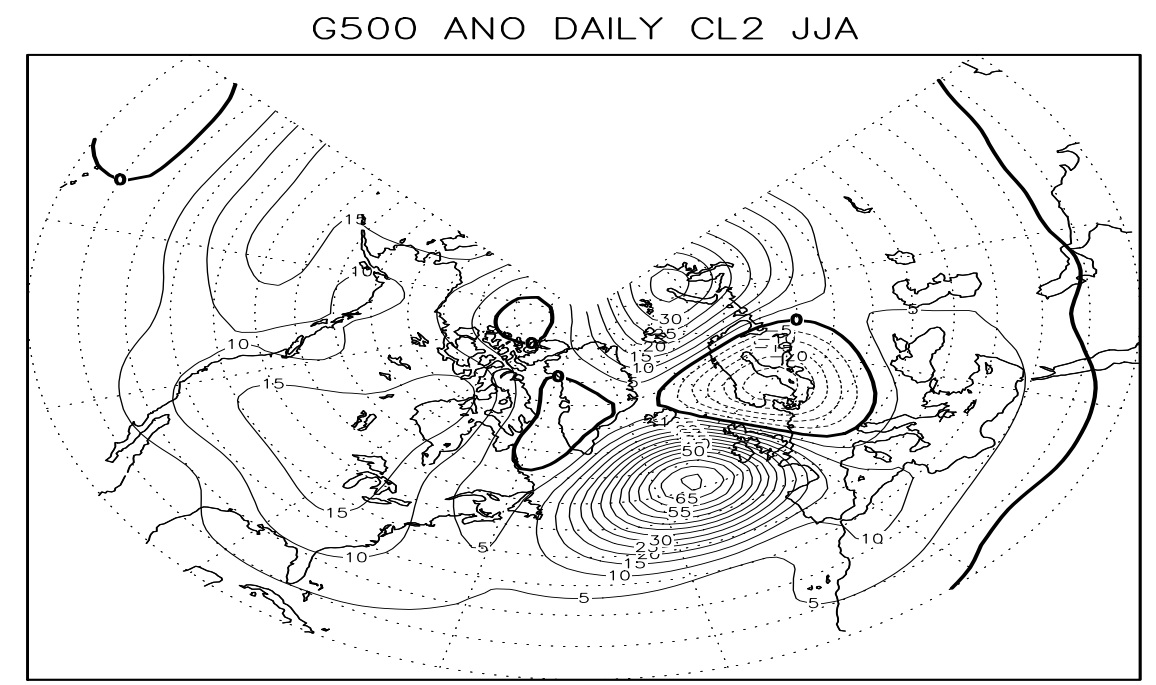

b)

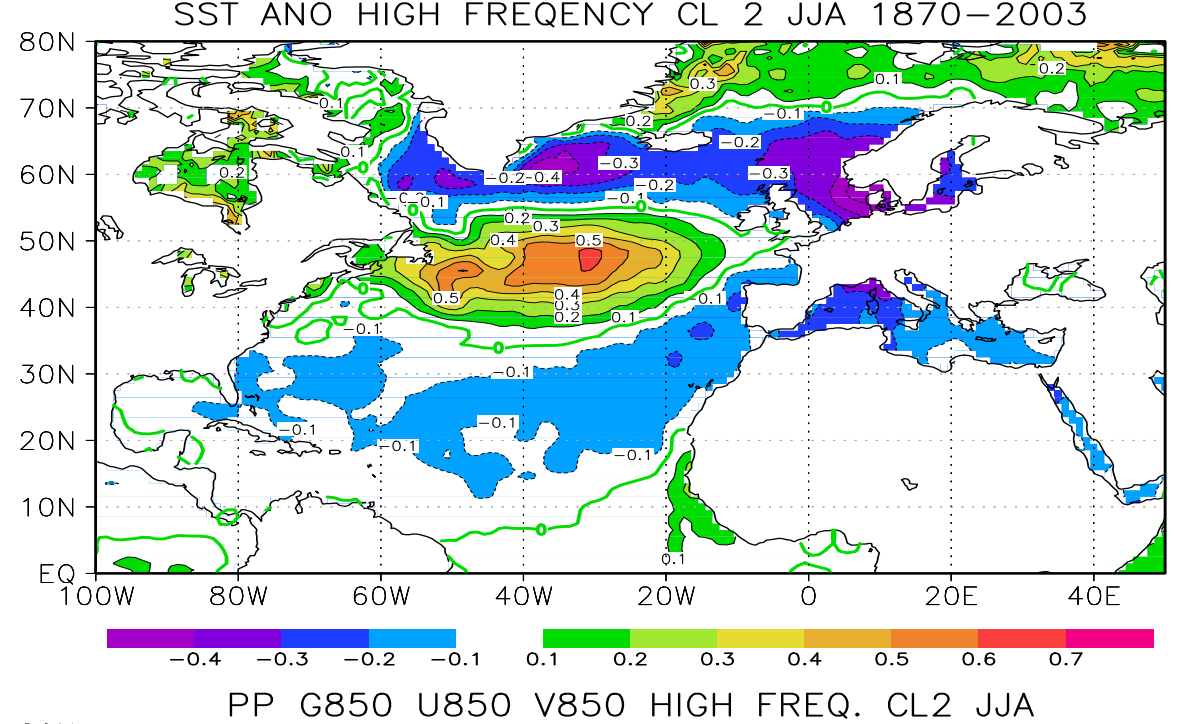

c)

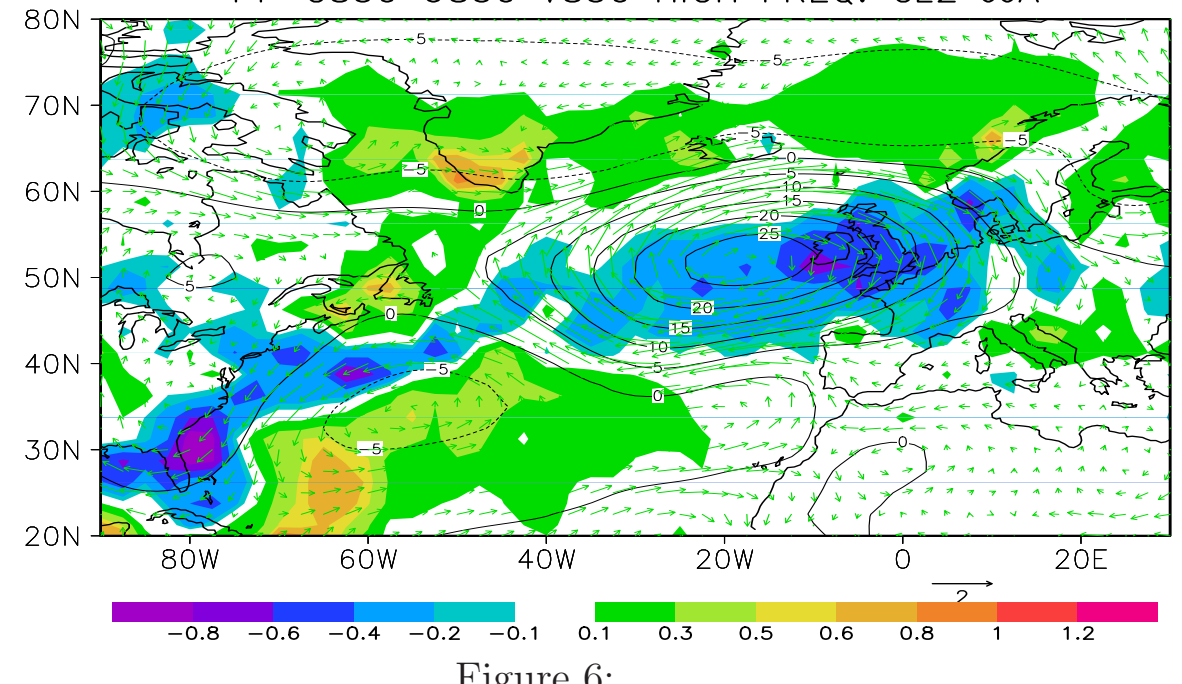

Figure 6: 
PC1-D18O DEUTERIUM CL2 JJA 7 RM

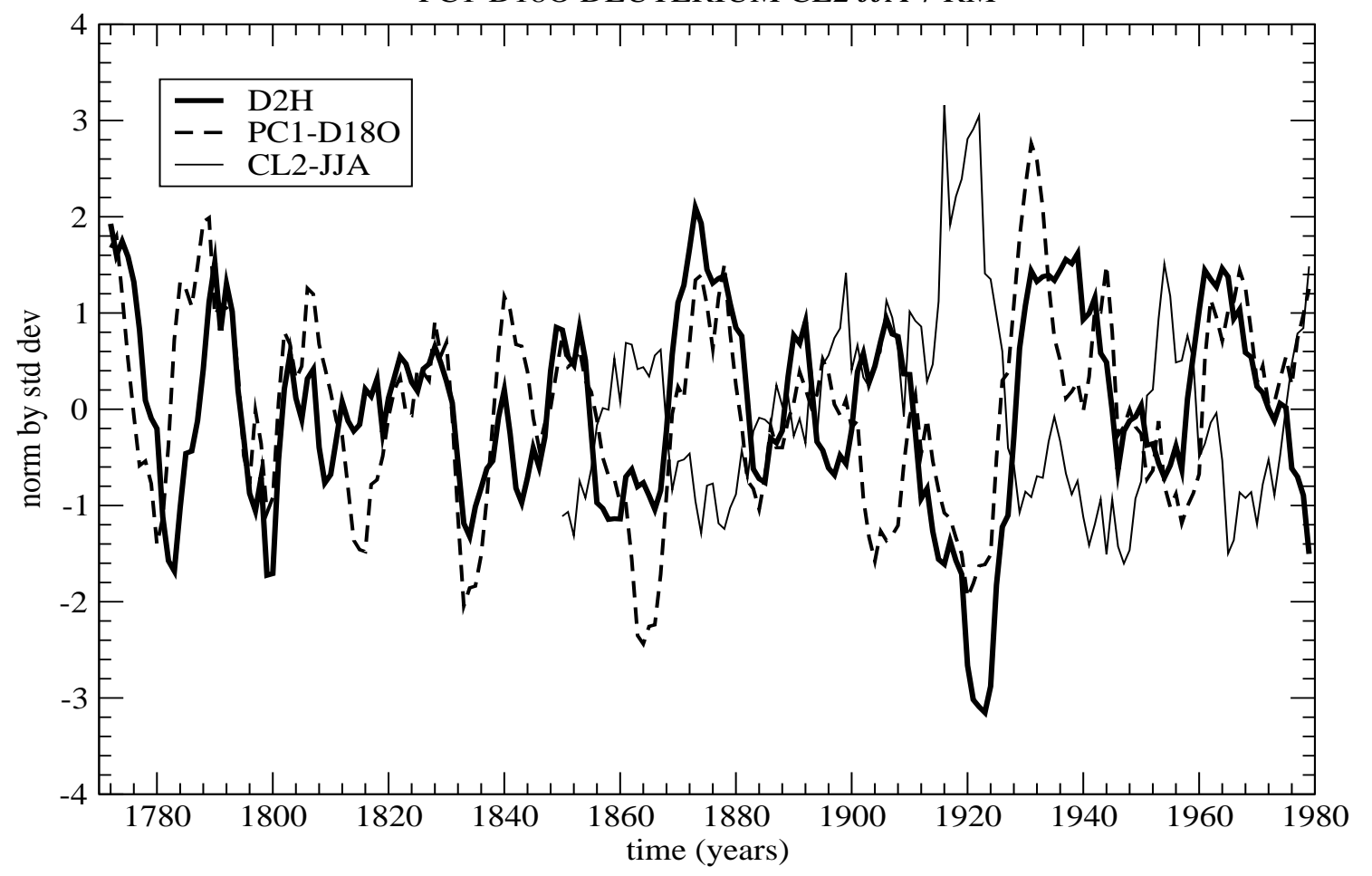

Figure 7: 
a)

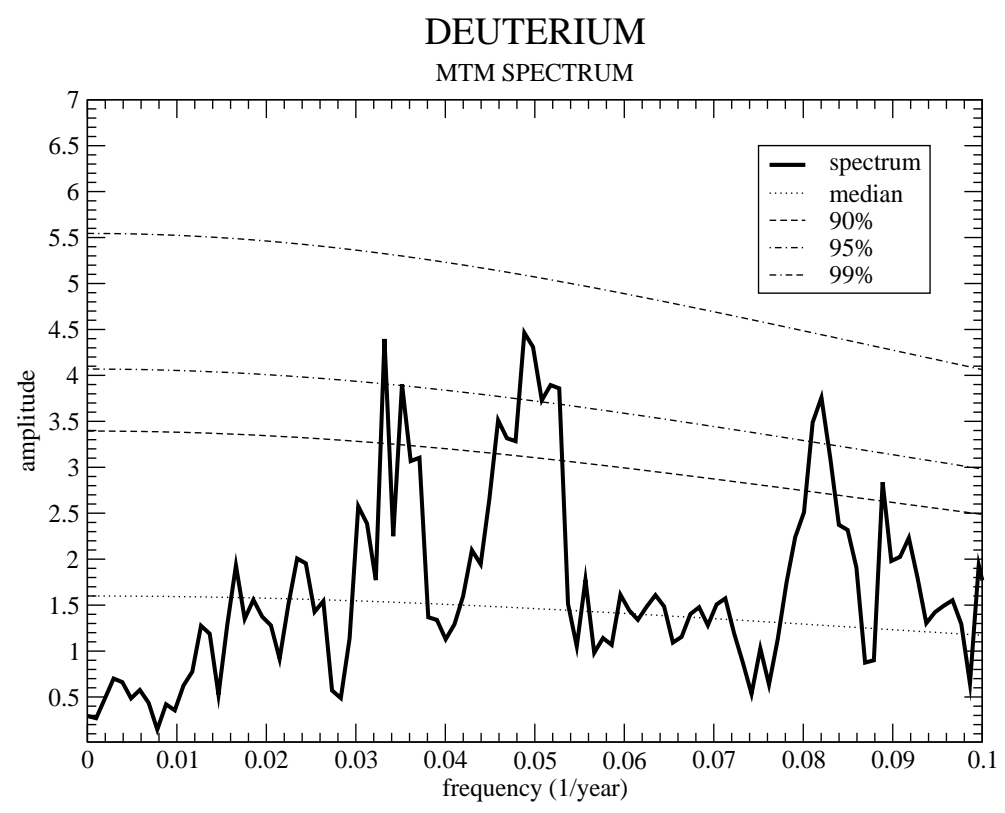

b)

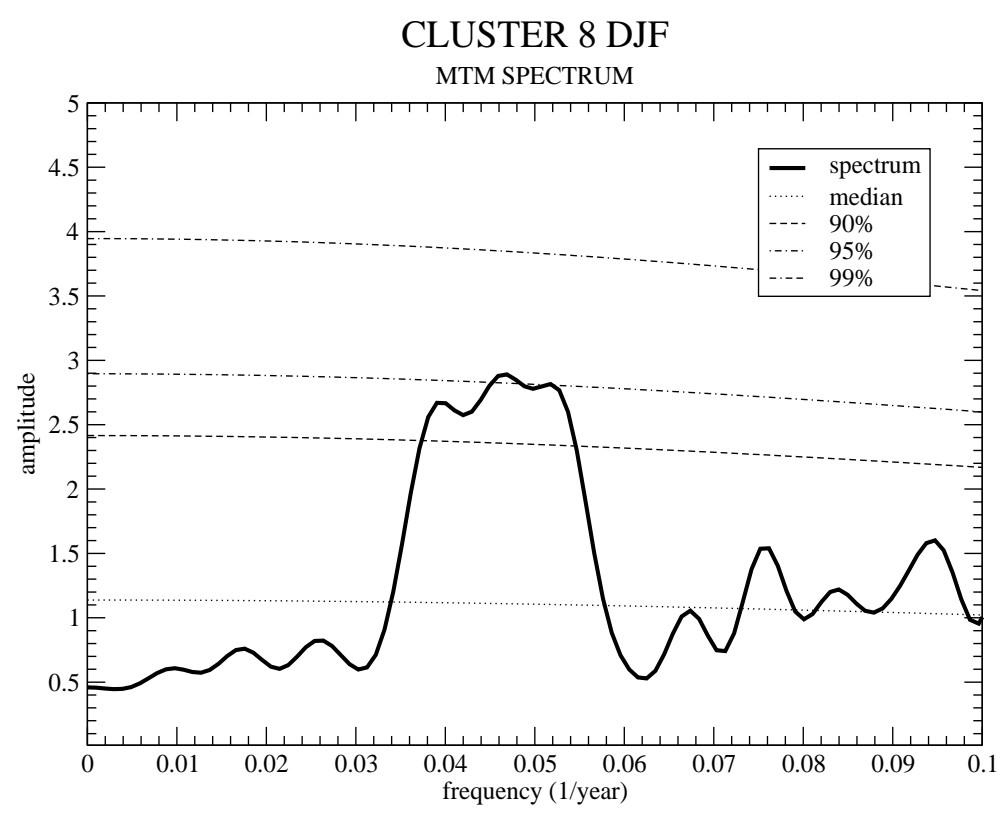

Figure 8: 